\title{
NO LIMIAR DO COTIDIANO ESCOLAR: ACÕES FORMATIVAS COM O PIBID PARA A APROPRIAÇÃO DA LEITURA POR ALUNOS DE EJA
}

\section{RESUMO}

Este artigo apresenta reflexão acerca de aspectos teóricos e práticos dos trabalhos desenvolvidos por bolsistas do Programa Institucional de Bolsa de Iniciação à Docência (PIBID), estudantes de Pedagogia da Universidade Federal do Rio Grande do Norte/UFRN, na Escola Municipal Prof ${ }^{a}$ Emília Ramos, Natal/ RN, Brasil, no ensino da modalidade Educação de Jovens e Adultos.A leitura é uma atividade do Sistema de Escrita Alfabético (SEA), que perpassa, inicialmente, pela decodificação, sendo essa a concretude e a finalidade da escrita.

Em geral, o professor realiza as mediações de ensino e, ao avaliar, remete apenas ao processo da escrita. Tal fato expõea dificuldade em realizar intervenções direcionadas ao processo de apropriação da leitura. Decorre disso privilegiar a reflexão sobre oficinas pedagógicas para a apropriação do SEA, realizadas com estudantes bolsistas PIBID e com docentes, nos dias de estudo e de assessoramento, assim como nas atividades de planejamento. Essas oficinas foram propostas pela coordenação pedagógica da escola, a partir da preocupação com os 
resultados insatisfatórios da aprendizagem. Consistiram em uma forma de contribuir para a articulação entre teoria e prática, indispensável à ação educativa dos estudantes bolsistas e das professoras colaboradoras. Visou-se, também, um incremento na qualidade das intervenções junto aos alunos da escola. Seus resultados incidiram nos projetos desenvolvidos pelos bolsistas PIBID.Avaliações de professores e pedagogos sobre as ações para a apropriação da leitura por aluno da EJA vêm mostrando ser o PIBID uma ação coerente e viável, pois vincula conteúdos trabalhados com a prática social, fundamentação teórica com práticas docentes.

Palavras chave: Iniciação à docência.

Formação continuada. EJA.

Apropriação da leitura.

\section{INTRODUÇÃO}

Este trabalho foi desenvolvido por supervisores e bolsistas do PIBID/Pedagogia-Natal/ UFRN, com a participação das professoras colaboradoras, na Escola Municipal Prof ${ }^{\mathrm{a}}$ Emília Ramos, na modalidade de Educação de Jovens e Adultos/EJA. As turmas foram do Primeiro Segmento, composto pelos I e II Níveis $\left(1^{\circ}\right.$ ao $5^{\circ}$ ano), e do Segundo Segmento, III e IV Níveis $\left(6^{\circ}\right.$ ao $9^{\circ}$ ano). Neste artigo, foca-se nas discussões realizadas no Primeiro Segmento, lócus de intervenção do PIBID na escola. As intervenções dos bolsistas estudantes se iniciam com a observação da sala de aula, com a participação nos planejamentos, com a elaboração do projeto a partir das necessidades dos jovens e adultos e com o diálogo com o professor colaborador e a coordenação pedagógica. Essa iniciativa permite o desenvolvimento da ação pedagógica e as atividades junto aos estudantes da EJA.

O trabalho tem como objetivo contribuir com a articulação entre teoria e prática no processo de ensino e de aprendizagem na apropriação da leitura, indispensável à ação educativa para a aquisição da alfabetização, realizado com os professores e estudantes bolsistas. Pretendemos, ainda, dar continuidade à formação em serviço às professoras colaboradoras para uma prática mais eficaz das intervenções junto aos estudantes da EJA, a partir dos planejamentos, das observações em sala de aula e do cotidiano, nas elaborações de sequências didáticas para o desenvolvimento dos planos de ensino que servirão como base para os projetos desenvolvidos pelos bolsistas PIBID-Pedagogia.

Para melhor entendimento, descreveremos como se dá a rotina escolar. O professor tem quatro dias de docência e um dia de planejamento semanal. Para tanto, a escola segue um cronograma institucional sugerido pela Secretaria Municipal de Educação e Cultura(SME) do município de Natal/RN, nas Diretrizes para o Funcionamento das Unidades de Ensino da Rede Municipal. O cronograma é organizado por dia, em que há um dia por semana no qual o professor se ausenta de sala de aula para realizar seu planejamento semanal. Enquanto o professor(a) planeja, outros professores assumem sua carga horária, que, no caso dos Primeiros Segmentos, são os professores de Ensino Religioso, Educação Física e Artes.

A Resolução No 003/2011- CME, Cap.III Da Organização do Trabalho Pedagógico, cita como se dá essa organização na rede de ensino em seuArt. 15 - O planejamento pedagógico dos professores dos Níveis I e II ocorrerá na unidade de ensino, semanalmente, das 19 às 22 h. Para os professores dos Níveis III e IV, o planejamento será por disciplina, sucedendo na unidade de ensino, semanalmente, das 19 às 22 h. Os dias do planejamento da EJA serão definidos conforme cronograma sugerido pelo SEJA/SME - Parágrafo Único: na oportunidade da realização de formação continuada promovida pela SME ou por ela autorizada, o 
professor terá sua participação garantida dentro do seu horário de planejamento pedagógico.

Toma-se como orientação, também, os Referenciais Curriculares da EJA (SME-Natal/ $\mathrm{RN}, 2008)$, que reafirmam a organização do espaço/tempo das escolas.Esses referenciais sugerem o cronograma convencional para toda rede de ensino municipal, com o intuito de desenvolver as atividades de planejamento, como é distribuído pelas Diretrizes para o Funcionamento das Unidades de Ensino da Rede Municipal (2012, p.32). Essas diretrizes estabelecem que "O professor cumprirá 16 (dezesseis) horas/aula de docência, distribuída em 04 (quatro) dias, ficando 04(quatro) horas disponíveis para o planejamento, conforme o cronograma sugerido pela SME para as unidades de ensino, possibilitando formação continuada do professor sem afastá-lo de sala de aula ".

Assim, as orientações institucionais partem do calendário semanal conforme as formações aos professores e aos coordenadores da rede de ensino, como pode ser visto nos quadros a seguir:

\begin{tabular}{|ccccc|}
\hline \multicolumn{4}{c|}{ CRONOGRAMA DE PLANEJAMENTO $1{ }^{\circ}$ SEGMENTO * } \\
\hline SEGUNDA FEIRA & TERÇA FEIRA & QUARTA FEIRA & QUINTA FEIRA & SEXTA FEIRA \\
\hline & I Nível & I Nível & \\
\hline II Nível & II Nível & \\
\hline
\end{tabular}

\section{Figura 1 - Calendário Semanal}

Fonte: Diretrizes para o Funcionamento das Unidades de Ensino da Rede Municipal (2012, p.31).

*A unidade escolar adapta à sua realidade um desses dois dias ou, se necessário, os dois.

\begin{tabular}{ccccc}
\hline \multicolumn{5}{c|}{ CRONOGRAMA DE PLANEJAMENTO } \\
\hline SEGUNDA FEIRA & TERÇA FEIRA & QUARTA FEIRA & QUINTA FEIRA & SEXTA FEIRA \\
\hline Arte & Língua Portuguesa & Matemática & Ciências & História \\
\hline Educação Física & & & Inglês & Geografia \\
\hline Ensino Religioso & & & \\
\hline
\end{tabular}

Figura 2 - Cronograma de Planejamento

Fonte: Diretrizes para o Funcionamento das Unidades de Ensino da Rede Municipal (2012, p.32).

A organização do cronograma dentro da rotina escolar estabelece um dia por semana, podendo estar sob a coordenação da equipe técnica escolar, ou fora da escola, sob a coordenação da equipe da Secretaria. Trata-se de um procedimento para assegurar e favorecer as relações entre a prática e a teoria no cotidiano escolar, dando oportunidade de todos participarem desses momentos de atividades pedagógicas. Vale ressaltar que fica a critério do professor a decisão de participar, ou não, do planejamento externo.
Ao mesmo tempo, a escola tenta zelar por esse espaço/tempo como momento de crescimento individual, profissional e educativo, com o objetivo de assegurar a qualidade em sua metodologia de planejamentos semanais, em que busca variar as estratégias adotadas, de acordo com as necessidades pedagógicas, tais como: dias de estudos - estudos compartilhados de textos/oficinas pedagógicas, planos de ensino diários/sequências didáticas, planos de eventos sociais, relatos de experiências, análise dos planos de ensino, informes, debates e assembleias com alunos e/ou professores. 
A formação docente, nesse contexto escolar, se dá na articulação com o contexto organizacional da instituição, pois é determinante quando a ação educativa tem uma atividade que assume um caráter da própria realidade. Como tal, tem a necessidade de refletir a prática docente junto aos bolsistas, ao coordenador e aos professores das intervenções, nas elaborações de situações de ensino e de aprendizagem, em específico para este estudo, na apropriação da leitura como ponto de partida para a aquisição do saber.

\section{NO LIMIAR DO COTIDIANO ESCOLAR}

O cotidiano escolar envolve uma dinamicidade de todos os partícipes de forma conceitual, emocional, afetiva e profissional. É nessa dinamicidade que os conhecimentos interagem,numa pedagogia de políticas cultural e social. Por isso, os momentos de planejamento são levados a sério, sendo iniciado com o cronograma semanal institucionalizado e sistematizado, para que possamos analisar, refletir e buscar alternativas, de forma fundamentada, a nossas incertezas, para a melhoria do processo de ensino e de aprendizagem. Por isso foi necessário, no contexto, proporcionar a cada partícipe a oportunidade de uma formação em serviço. Foi, então, que se voltou para uma formação que nos possibilitasse ser agentes intelectuais da transformação escolar, como ponto de partida para uma qualidade de ensino.

As análises se centraram na maior dificuldade dos estudantes, a leitura, com as intervenções, na maioria das vezes, na prática das professoras e dos bolsistas (sob orientação das professoras colaboradoras), sendo feitas no âmbito individual, nos momentos de "reforço escolar", a partir das próprias produções do estudante, quando da análise linguística/verificação da escrita (registro), com a consciência fonológica no processo de decodificação.

Percebemos que, ao fazerem o registro dos resultados de aprendizagem no processo de alfabetização, as professoras contemplavam, com mais segurança,os níveis de escrita, no entanto, não tinham tanta segurança em relação à leitura. A prática desses processos era questionada, indicando a falta de segurança sobre as intervenções e sobre a avaliação da leitura. Decorre disso a consistência no levantamento dos níveis de leitura, nas respostas dos docentes no levantamento era contraditória ou vaga. Partimos, então, para as observações realizadas no ato de planejar as sequências didáticas, nas discussões sobre a avaliação, nas intervenções das análises dos levantamentos dados do quadro de aprendizagem da alfabetização.

Analisando as atividades de apropriação da leitura dos alunos, no processo de ensino da apropriação do SEA, no momento da atividade, eles agiam de forma assistemática, às vezes intuitivamente, uma vez que tinham a necessidade de ter em mãos o registro-escrita, pois, para eles, o registro é algo palpável. Contudo, ficavam muito ansiosos e apreensivos, com medo de falar o que significavam as letras. Tal fato pode ser diagnosticado como um momento da reflexão da análise linguística da palavra (estratégia da decodificação), para o processo da análise linguística, desde a função do SEA, o letramento, até a forma das letras e a consciência fonológica da apropriação da leitura.

Ao trabalhar nessa perspectiva, realizamos um estudo com os professores da Modalidade EJA e com os estudantes bolsistas/PIBID. Observamos que, geralmente, os professores discutiam nos planejamentos a aquisição e aavaliação das produções de escrita dos alunos, mas não relatavam intervenções específicas do Direito de Aprendizagem do Eixo da Leitura (BRASIL, 2012). Ao realizar uma reflexão com 
os alunos sobre suas produções escritas, os professores justificavam que estavam realizando intervenções na leitura também, argumentando que existiam intervenções com estratégias de apropriação da leitura, porém estavam somente checando a consciência fonológica no ato de notar/registrar o sistema. Ou seja, o professor pensava que estava trabalhando a leitura no ato da checagem da escrita, mas que, na verdade, estava apenas realizando a análise linguística da produção.

Foi observado que os envolvidos nesse processo de ensino e de aprendizagem geralmente não contemplavam,de forma direta, intencional e consciente, as intervenções para a leitura em suas sequências didáticas. A leitura é uma das primeiras habilidades para o processo de alfabetização e um dos eixos da Língua Portuguesa que, consequentemente, implica em outro eixo, o da análise linguística para a apropriação do SEA de maneira mais específica, com questões registradas de forma mais direcionada para reflexão da consciência fonológica. Apesar disso, o professor, muitas vezes, não consegue elaborar uma sequência didática própria para as intervenções na apropriação e no desenvolvimento da leitura na fase inicial dessa aprendizagem.

A consciência fonológica, por ser uma atividade mental em que o aluno reflete sobre os segmentos sonoros das palavras, é algo muito subjetivo. Portanto, o professor necessita elaborar uma sequência didática bem detalhada, com questionamentos que levem o aluno a fazer relações e conexões entre o grafema e o som. Para Morais (2012, p. 84), a consciência fonológica "é um conjunto de habilidades que envolve variações de operações mentais que fazemos sobre as partes das palavras pronunciadas; é capacidade metalinguística que permite analisar e refletir, de forma consciente sobre a estrutura fonológica da linguagem".

Desse modo, verificamos que a maioria desses professores e bolsistas realizava com mais firmeza as intervenções do processo de apropriação da escrita e somente contemplava a leitura na análise linguística da produção escrita. Para Cagliare (2009, p. 131),

[...] o ato de ler é uma atividade muito
complicada, e que a leitura é a realização da
finalidade da escrita. Em geral, o professor,
ao avaliar, se remete apenas ao processo da
escrita. O que nos mostra a dificuldade de re-
alizar intervenções direcionadas ao processo
de apropriação da leitura.

Sabe-se que a língua materna nos favorece na aquisição da escrita em suas variações linguísticas para a apropriação do sistema de escrita - SEA. Para o acesso a esse sistema, é necessária a aquisição da leitura. Esta tem como base o alfabeto, cuja invenção foi

[...] decisiva porque é um sistema que permi-
te representação da linguagem com maior
economia de meios, mas sua abstração tem
como consequência o fato de que os falantes
não podem adquiri-lo facilmente "fixan-
do-se" na decomposição das palavras, mas
devem basear-se em métodos e instrução
e no confronte com a própria linguagem
escrita para alcançar o nível de consciência
fonológica que se requer para seu domínio
(COLOMER, 2002. p.13).

Morais (1996) reforça dizendo que o alfabeto é um instrumento do SEA. Segundo o autor, "A invenção [...] Suscitou uma das mais importantes descobertas científicas da história da humanidade, provavelmente a primeira grande incursão do homem no seu inconsciente cognitivo e que se dá inicialmente pela leitura por meio dos sons".Ele acrescenta que "Os sons das palavras evocam inevitavelmente letras, como também não deixam de despertar sentidos. No nosso sistema mental, as representações semânticas, fonológicas e ortográficas das palavras comunicam de maneira totalmente interativa[...]".O pesquisador apregoa que, para alfabetizar, "[...] precisa decifrar ou dar conta de dois enigmas ou questões principais: $\mathbf{O}$ que as letras representam (ou nota, ou substituem)? Como as letras criam representações [...](grifos do autor)". Nesse sentido, conclui Morais: "Quando nos 
apropriamos de qualquer sistema notacional, temos que compreender e internalizar suas regras ou propriedades e aprender suas convenções (MORAIS, 1996. p. 46-64).

Todo esse processo deverá anteceder o momento de registro do SEA, para que os alunos tenham conhecimento e informações para a produção escrita. É isso que o professor, por falta de informação devido à própria formação em sua profissionalização acadêmica e em serviço, não consegue mediar, de forma intencional, a leitura no ato da elaboração da sequência didática nem, consequentemente, executá-la conscientemente.

Apesar de tudo, os professores conseguem realizar uma reflexão da leitura de forma "intuitiva", via intervenção da apropriação da escrita. Ou seja, no momento de intervenção, utilizam a estratégia de checagem para a leitura da produção de escrita de palavras, mas muitas vezes, não chegam a mediar o processo de alfabetização na apropriação da leitura. Com isso, o aluno é quem mais faz esforço para apropriar-se da habilidade de leitura, pois a sua aprendizagem se dá por meio da produção textual, no ato da checagem da escrita. Contudo, o professor ainda consegue, com muito esforço, que os envolvidos passem para nível superior, mas com muita perda de tempo e de energia, formando poucos alfabetizados.Mesmo assim, os alunos conseguem chegar a decodificar no primeiro nível. Apesar de se deterem por mais tempo e tendo mais experiências na linguagem oral, conseguem realizar relações e conexões com as informações cotidianas. Como afirma Ferreiro (1999, p. 27),

\begin{abstract}
A aprendizagem da leitura, entendida como o questionamento a respeito da natureza, função e valor desse objeto cultural que é a escrita, inicia-se muito antes do que a escola imagina, transcorrendo por insuspeitados caminhos. Que além dos métodos, dos manuais, dos recursos didáticos, existe um sujeito que busca a aquisição de conhecimento, que se propõe problemas e trata de solucioná-los seguindo sua própria metodologia.
\end{abstract}

Apesar da autonomia dos alunos, como afirma Ferreiro (1999, p. 27), a professora e os estudantes bolsistas, por sua vez, ao participarem da primeira parte da Oficina Pedagógica sobre a Apropriação da Leitura, perceberam as lacunas pedagógicas nas intervenções da apropriação da leitura. Além disso, ao socializarem os resultados do ano de 2014, eles já socializavam o desejo de aprofundar e colocar em prática as novas informações. Isso fica demonstrado nos resultados finais do ano de 2014, no quadro a seguir.

\begin{tabular}{cccccc} 
NÍVEL & APROVADOS & REPROVADOS & TRANSFERIDOS & ABANDONOS & TOTAL \\
\hline I & 17 & 17 & - & 06 & 40 \\
\hline
\end{tabular}

Figura 3 - Oficina Pedagógica sobre a Apropriação da Leitura

Fonte: Quadro de resultado final/2014 modalidade EJA - Nível I. Escola Municipal Professora Emília Ramos.

Esse resultado, estatisticamente baixo, tem uma explicação: a carga horária da noite é reduzida (de quatro horas e meia para duas horas e meia), há uma rotatividade de alunos (devido às necessidades de sobrevivência - empregos com horários rotativos), greve e muitos imprevistos que interferem no aproveitamento da aprendizagem. Ademais, os alunos que se matriculam sem Histórico Escolar migram, às vezes, para níveis mais avançados. 


\section{PROCESSOS METODOLÓGICOS}

O saber, como um conhecimento processual, deve usar estratégias especificas para cada conhecimento contextual. Para tanto, foi necessário atentar para cada partícipe do grupo, tais como: os estudantes bolsistas recém chegados, os professores colaboradores e o mediador desse processo, o coordenador pedagógico. O processo metodológico iniciou-se com as observações do coordenador pedagógico nos momentos de planejamento e na sua concretude, no plano escolar, em específico, na elaboração da sequência didática e nos levantamentos de aprendizagem da apropriação do SEA.

Em cada momento de planejamento, houve discussão sobre as duas habilidades existentes no SEA. Foi notório aos participantes a ausência sistemática da apropriação da leitura,no momento em que foi solicitado um levantamento dos níveis de leitura e de escrita. Nesse instante, houve muitos questionamentosa respeito do nível, das hipóteses,do ritmo de leitura e de como se dava a avaliação.

Logo de imediato, questionamos como eles elaboravam uma sequência didática para as intervenções da apropriação e do desenvolvimento da leitura. Percebemos que a maioria tinha mais segurança na elaboração de intervenções no processo da apropriação da escrita do que da leitura.

Diante dessas situações, elaboramos uma oficina pedagógica com intervenções de estudo sobre os conceitos básicos de leitura e uma sequência didática para a apropriação dessa habilidade. As oficinas ocorreram nos dias de estudo e de assessoramento e nas atividades de planejamento. Consistiram em uma forma de contribuir para a articulação entre teoria e prática, indispensável à ação educativa dos bolsistas e dos professores colaboradores da modalidade EJA. Visavam, também, um incremento na qualidade das intervenções junto aos alunos.

\section{RESULTADOS}

Acreditamos que o estudo dessa natureza possa gerar novas mudanças de atitudes do profissional educador e de todos os envolvidos nesse processo. Segundo Fazenda (2003, p. 75), podemos compreender a adesão dos participantes em

[...] atitude de humildade ante a limitação do próprio saber, atitude de perplexidade ante a possibilidade de desvendar novos saberes; atitude de desafio, desafio ante o novo, desafio em redimensionar o velho; atitude de envolvimento e comprometimento com os projetos e com as pessoas neles envolvidas; atitude, pois de compromisso em construir sempre da melhor forma possível; atitude de responsabilidade, mas sobretudo, de alegria, de revelação, de encontro, enfim, de vida.
A maioria dessas atitudes fluiu de acordo com cada um, considerando cada situação vivenciada durante o trabalho. Enfim, analisamos algumas mudanças atitudinais no comportamento dos professores, dos estudantes/ bolsistas, do coordenador, dos estudantes e dos demais professores e profissionais do segmento escolar, como os professores das áreas do Segundo Segmento ( $5^{\circ}$ ao $9^{\circ}$ ano), em relação à importânciado monitoramento da leitura como acesso à cidadania. Isso teve um reflexo no comportamento dos envolvidos, conforme os exemplos elencados a seguir. 


\section{MUDANÇAS INTRODUZIDAS NA PRÁTICA DAS PROFESSORAS COLABORADORAS}

Após a participação nos estudos e na oficina de leitura, as professoras colaboradoras começaram apercebere a identificar as habilidades do SEA (leitura e escrita), assim como as suas atividades adequadas para a apropriação e para o desenvolvimento da leitura. Elas passaram a ficar atentas àelaboração da sequência didática específica para a leitura. As práticas de uma professora ledora estão planejadas conforme o nível e a necessidade das intervenções, deixando, assim, o estudante com desafios de acordo com seu nível e com sua motivação.

\section{MUDANÇAS NO OLHAR DO BOLSISTA PIBIDIANO}

Os bolsistas estão mais atentos à prática da professora colaboradora e às intervenções de leitura com a turma no grande grupo e em grupos produtivos. Percebem a importância do cotidiano escolar para a sua formação profissional. Enfim, já conseguem contemplar,no seu projeto, a importância da leitura nos processos de apropriação e de desenvolvimento.

\section{CONSISTÊNCIA DAS MEDIAÇÕES DO COORDENADOR}

O coordenador pedagógico, inicialmente, percebeu um pouco de rejeição por parte de alguns professores. No entanto, no decorrer do processo, (re)planejamos, dividindo o grande grupo e delineando duas oficinas para atender, de forma mais direta, as particularidades de cada nível. Contudo, os dois segmentos apresentam necessidades em comum, sendo necessário um estudo dos dois grupos. Depois da aplicação da oficina, surgiu a ideia de um grande projeto que atendesse toda a clientela da EJA,em relação à questão da leitura para o próximo ano letivo.

\section{CONSCIÊNCIA NAS ATITUDES DOS ESTUDANTES}

Percebemos que os alunos que tinham dificuldade na leitura procuravam a coordenação para um reforço escolar, principalmente os estudantes do Segundo Segmento. Quanto ao

Primeiro Segmento, ( $1^{\circ}$ e $2^{\circ}$ níveis $)$, eles deram um salto qualitativo na habilidade de leitura, em relação aos anos anteriores.

\section{MUDANÇAS INTRODUZIDAS NA \\ PRÁTICA DE LEITURA NA ESCOLA}

A participação do grande grupo nas discussões sobre a leitura ficou mais consistente e os professores ficaram mais atentos no monitoramento dos níveis de leituras dos seus alunos. 


\section{DISCUSSÕES}

A escola, como um lugar de aquisição de conhecimentos, tenta desenvolver uma proposta que atenda às reais necessidades do processo de ensino e de aprendizagem. É um espaço de saberes, tanto para os estudantes como para os profissionais que nele desenvolvem seu trabalho, em prol do desenvolvimento intelectual, afetivo e social nas mais variadas dimensões educativas, tendo a parte pedagógica como o eixo de sustentação de sua função. Essa proposta pretende que os estudantes, além dos professores que fazem parte do processo de ensino e dos estudantes bolsistas, desenvolvam a habilidade de leitura,pois precisam perceber a importância desse processo por meio da formação em serviço.

A oficina surgiu diante das dificuldades em se realizar intervenções no processo de apropriação da leitura. A cada socialização dos relatos de experiências e dos resultados das professoras e dos estudantes bolsistas, eles já demonstraram interesse em refletir de forma mais sistematizada e coletiva, buscando o planejamento de forma consistente e tentando levar as novas possibilidades de melhorarem o processo de ensino e de aprendizagem da leitura. Nos anos subsequentes, já se posicionam com indícios de adesão à nova proposta pedagógica.

Em oficinas pedagógicas sobre a aquisição da leitura esobre a consciência fonológica, as professoras perceberam que não planejavam ações específicas para o momento da apropriação da leitura. Elaboravam, geralmente, uma sequência didática para a aquisição da escrita e, ao mesmo tempo, para a leitura como checagem/avaliação da escrita. Surgiram muitas dúvidas em relação ao processo de ensino e de aprendizagem da leitura nos momentos da apropriação, como mediadores do processo em relação aos direitos de aprendizagem, às propriedades do SEA, às hipóteses, aos tipos, às práticase aos níveis de leitura e até de escrita.

Nas oficinas, observamos que a maior atenção dos participantes recaiu sobre os níveis, sobre as hipóteses de leitura e sobre como intervir no momento da decodificação de letras, palavras e frases. Reiteramos que toda intervenção de leitura deve partir do coletivo, de forma que o mediador chame a atenção do grafema e da sonoridade, apontando para a lousa, para o direcionamento do olhar, relacionando com as conexões da consciência fonológica das palavras. As frases são selecionadas e retiradas de textos já compreendidos pela turma.

Ressaltamos que todo alfabetizador deve ter o entendimento sobre a leitura/escrita e que é necessário o conhecimento de conceitos pedagógicos básicos, tais como métodos de ensino para apropriação do SEA, dimensões da leitura, propriedades do SEA (MORAIS, 2012), etapas do processo de apropriação da leitura, dos níveis de leitura - rota lexical, as hipóteses (KATO, 1999) -, estratégias de leitura, além de gêneros, sequências textuais, portador, formas, ritmos e compreensão (em níveis pontual e global).

Alfabetizar é uma atitude profissional das mais importantes para o desenvolvimento das linguagens. Nesse sentido, a leitura (níveis de processo fonológico e visual) é um dos primeiros passos. Segundo Dehaene(2012, p.54), "A leitura de uma palavra empresta vias paralelas do tratamento da informação(...) podemos compará-las a léxicos mentais que associam a sucessão de fonemas ao significado".

Para tanto, no adulto, essas vias ficam mais difíceis e, ao mesmo tempo, mais fáceis em relação à criança. No adulto, é mais difícil, pois ele já vem cansado, com traumas no processo de aprendizagem e com baixa autoestima. Por outro lado, é mais fácil por já ter uma leitura de mundo, o desejo de aprender e muita experiência. Daí a importância da relação teoria versus prática,pois, na maioria das vezes, o ativismo limita as novas alternativas de ensino e de aprendizagem e entrava intervenções que favorecem uma mediação na apropriação do conhecimento. 
Em relação aos projetos desenvolvidos pelos estudantes bolsistas PIBID/Pedagogia, eles tiveram foco na alfabetização, destacando-se os eixos de Língua Portuguesa, assim descritos nas orientações da proposta do Pacto pela Alfabetização na Idade Certa, para os três primeiros anos do Ensino Fundamental:
São descritos direitos de aprendizagem gerais, que permeiam toda a ação pedagógica e depois são expostos quadros com conhecimentos e capacidades específicos organizados por eixo de ensino da Língua Portuguesa:Leitura, Produção de textos Escritos, Oralidade, Análise Linguística (BRASIL, 2012. p.44).

\section{CONCLUSÕES}

O percurso do processo ensino e aprendizagem da apropriação da leitura se deu de forma intencional, objetivando a adesão do professor e do estudante bolsista PIBID, no sentido de despertar para a relação teoria versus prática, em busca do aprimoramento da qualidade do ensino do alunado da EJA. Notamos, hoje, maior preocupação de professoras colaboradoras e de estudantes bolsistas PIBID em aprimorarem os conhecimentos acerca da apropriação da leitura em suas variadas etapas,ao longo do processo de ensino e de aprendizagem: níveis de leitura, hipóteses de leitura, propriedade do SEA e etapas de leitura em nível de decodificação e de compreensão.

Verificamos que a dinâmica da escola influencia, no que diz respeito aos aspectos pedagógicos, na formação de professores e de bolsistas, nesse caso, a formação para a apropriação da leitura. Professores e pedagogos estão conscientesde ser o PIBID coerente $\mathrm{e}$ viável, pois vincula conteúdos trabalhados com a prática social e com a fundamentação teórica para docentes e equipe técnico-pedagógica. Por meio desse encaminhamento, os alunos/bolsistas vêm demonstrando mais interesse pelos conteúdos escolares e, ao mesmo tempo, instigando os professores colaboradores e a equipe pedagógica a buscarem mais alternativas para uma prática coerente com fundamentos teóricos, para melhor qualidade do processo ensino e aprendizagem.

Verificamos, também, que todo profissional, no seu lócus de trabalho, necessita estar aberto a novas gerações de profissionais em formação. Do mesmo modo, precisa dar testemunho do conhecimento acumulado no decorrer de sua história na instituição em que atua. 


\section{IN THE THRESHOLD OF THE SCHOOL DAILY:FORMATIVE ACTIONS WITH PIBID FOR THE APPROPRIATION OF READING BY EJA STUDENTS}

\section{ABSTRACT}

This paper discusses the theoretical and practical aspects of the work developed by students with scholarships from the Institutional Program of Teaching Initiation in the modality of Youth and Adults Education at the Escola Municipal Prof ${ }^{\mathrm{a}}$ Emília Ramos, Natal/RN, Brazil. Reading is an activity of the Alphabetical Writing System, in which decoding is an essential procedure. Such a phase denotes the concreteness and objective of the writing. In general, the teacher performs the education mediations and rely only on the writing in order to assess the student learning. This fact leads to difficulties in performing interventions in the reading process. We focus on understanding the role of pedagogical workshops in the mastering of the Alphabetical Writing System. Such workshops were performed with scholarship holders and teachers during the study, assistance and planning activities. These seminars were proposed by the school's pedagogical direction in order to mitigate poor results in the assessment of their teachers' education. The proposed workshops contributed to the compromise between theory and practice, which is fundamental to the teaching activities of the scholarship holders and teachers. We also aimed at improvement of the interventions towards the students. The results had a positive impact on the projects carried out by the scholarship holders. The assessment performed by teachers on the activities for mastering reading in the Youth and Adults Education has shown that such a grant program is, in fact, an effective and viable solution, as it links course contents to social practices and theoretical basis to teaching practices.

Keywords: Introduction to teaching.

Continuingeducation. EJA.

Appropriation of reading.

\section{RESUMEN}

En este artículo se reflexiona sobre los aspectos teóricos y prácticos de la obra de semejantesdel Programa Institucional de Beca de Iniciación a la Docencia/PIBID / Pedagogía - UniversidadFederal do Rio Grande do Norte/UFRN, en la Escuela Municipal Profesora Emília Ramos, Natal/ RN, Brasil la educación de la modalidad de educación de jóvenes y adultos. . La lectura es una actividad del Sistema de Escritura Alfabética (SEA) que atraviesa inicialmente por la decodificación y ésta es la concreción y finalidad de la escritura. En general, el profesor realiza las mediaciones de enseñanza y, al evaluar, se remite sólo al proceso de la escritura. Lo que nos muestra la dificultad de realizar intervenciones dirigidas al proceso de apropiación de la lectura. De ahí privilegiamos la reflexión sobre los talleres de enseñanza para la apropiación del sistema de escritura alfabética (SEA), realizado con estudiosos PIBID y maestros en los días de estudio, asesoramiento y en las actividades de planificación. Dichos talleres fueron propuestos por la coordinación pedagógica, a partir de la preocupación por los resultados insatisfactorios de aprendizaje de los estudiantes. Consistían en una manera de contribuir a la articulación entre la teoría y la práctica, que es esencial para los compañeros de acción educativa y profesores colaboradores. Apuntaron también un 
aumento en la calidad de las intervenciones con los estudiantes. Sus conclusiones se centraron en proyectos desarrollados por compañeros PIBID. Las evaluaciones realizadas por los profesores y educadores, acerca de las acciones para la apropiación de la lectura por estudiante en la educación de adultos, ha demostrado ser el PIBID una acción coherente y factible, ya que se vincula contenidos trabajados con la práctica social, la base teórica con las prácticas de enseñanza. A través de esta referencia, los estudiantes / investigadores han mostrado más interés en las materias escolares.

Palabras clave: Introducción a la enseñanza. La educación continua. EJA. La lectura de la propiedad.

\section{REFERÊNCIAS}

BRASIL. Ministério da educação - MEC. Secretaria de Educação Básica.Referenciais Curriculares da EJA. Brasília: MEC. SEB, 2008.

Pacto Nacional pela Alfabetização na Idade Certa: Currículo no ciclo de alfabetização, Perspectivas para uma educação do campo.Unidade 1. Brasília: MEC/SEB, 2012.

CAGLIARI, Luiz Carlos. Alfabetização \& Linguística. São Paulo: Scipione,2009.

COLOMER, Teresa. Ensinar a ler, ensinar a compreender. Porto Alegre: Artmed, 2002.

DEHAENE, Stanislas. Os neurônios da leitura: como a ciência explica a nossa capacidade de ler. Tradução: Leonor Scliar-Cabral. Porto Alegre: Penso, 2012.

FAZENDA, Ivani. Interdisciplinaridade: qual o sentido? São Paulo: Paulus, 2003.

FERREIRO, Emília. Com Todas as Letras. São Paulo: Cortez, 1992.

KATO. Mary Aizawa. O aprendizado da leitura. 5. ed. São Paulo: Martins Fonte, 1999.

MORAIS, José. A arte de ler. São Paulo: UNESP. 1996.

MORAIS, Artur Gomes de. Sistema de escrita alfabética. São Paulo: Melhoramentos, 2012.

SEGRETARIA MUNICIPAL DE EDUGAÇAO - SME. Prefeitura Municipal Do Natal.

Resolução No 003/2011- CME. Cap. III - Da Organização do Trabalho Pedagógico. Natal, RN, 2011. 